March 2018

\title{
Treatment of a Rare Vascular Complication of Coronary Stenting in an Octagenarian
}

Hunaina Shahab

Aga Khan University, hunaina.shahab@aku.edu

Bilal Hussain

Aga Khan University, bilal.hussain@aku.edu

Nasir Rahman

Aga Khan University, nasir.rahman@aku.edu

Fateh Ali Tipoo Sultan

Aga Khan University, fatehali.tipoo@aku.edu

Follow this and additional works at: https://ecommons.aku.edu/pakistan_fhs_mc_med_cardiol Part of the Cardiology Commons

\section{Recommended Citation}

Shahab, H., Hussain, B., Rahman, N., Sultan, F. (2018). Treatment of a Rare Vascular Complication of Coronary Stenting in an Octagenarian. JCPSP:Journal of the College of Physicians and Surgeons--Pakistan., 28(3), s9-s10.

Available at: https://ecommons.aku.edu/pakistan_fhs_mc_med_cardiol/47 


\title{
Treatment of a Rare Vascular Complication of Coronary Stenting in an Octagenarian
}

\author{
Hunaina Shahab, Bilal Hussain, Nasir Rahman and Fateh Ali Tipoo Sultan
}

\begin{abstract}
The ability of drug-eluting stent (DES) to inhibit intimal proliferation has resulted in a massive increase in their usage over the years. However, it is known that the application of DES can alter the normal cascade of vascular healing, resulting in delayed endothelialisation with risk of vascular complications. Coronary artery aneurysms (CAN) are defined as more than $50 \%$ dilatation of the coronary artery compared to the reference vessel diameter with the reported incidence after percutaneous intervention $(\mathrm{PCl}$ ) being only around 0.35 to $6.0 \%$. Previously, CAN had been reported with the use of bare metal stent secondary to stretch, stent fracture and dissection. However, recently, increasing number of cases have been reported describing CAN after DES implantation. To the best of the authors' knowledge, they present the first case from Pakistan of a left anterior descending coronary artery aneurysm after DES implantation treated successfully with stenting under intravascular ultrasound guidance.
\end{abstract}

Key Words: Coronary vessels. Aneurysm. Stents.

\section{INTRODUCTION}

Coronary artery aneurysms (CAN) are defined as more than $50 \%$ dilatation of coronary arteries compared to reference vessels diameter, ${ }^{1}$ with incidence of 0.35 to $6.0 \% .2,3$ Previously, CAN had been reported with bare metal stents (BMS) secondary to stretch, stent fracture and dissection. ${ }^{2}$ Recently, increasing number of cases report CAN after drug-eluting stent (DES) implantation. 4,5

To the best of the authors' knowledge, the first case presented from Pakistan of a left anterior descending (LAD) CAN after DES implantation treated successfully with stenting.

\section{CASE REPORT}

An 85-year lady with a history of percutaneous intervention $(\mathrm{PCl})$ to left anterior descending $L A D$ with CypherTM stent (DES) in 2007, presented to the Emergency Department of The Aga Khan University Hospital with increasing restlessness and cough. She had a pulse of 110 beats/minute, respiratory rate of 40 breaths/minute and blood pressure of $90 / 60 \mathrm{mmHg}$. She had bibasilar crepitations on auscultation and troponin-I of $10.5 \mathrm{ng} / \mathrm{ml}$. Her electrocardiogram (ECG) showed old left bundle branch block. Transthoracic echocardiogram showed an estimated ejection fraction of $25-30 \%$ with akinetic apex, septum, mid anterior segments along

Section of Cardiology, Department of Medicine, The Aga Khan University Hospital, Karachi.

Correspondence: Dr. Hunaina Shahab, Resident Cardiology,

Department of Medicine, The Aga Khan University Hospital,

Stadium Road, Karachi.

E-mail: hunaina.shahab@gmail.com

Received: July 12, 2017; Accepted: October 31, 2017. with mild-moderate aortic stenosis and moderate mitral regurgitation.

She underwent a left heart catheterisation via right femoral artery $6 \mathrm{~F}$ sheath (Cordis $\AA$ ). Left coronary system was visualised using JL4 6F' catheter showing short left main vessel bifurcating into LAD and left circumflex vessels (LCx). LAD had tight in-stent re-stenosis (ISR) in the proximal part of previous stent (Cypher $2.5 \times 23 \mathrm{~mm}$ ), followed by CAN (Figures $1 \mathrm{~A}$ and $1 \mathrm{~B}$ ). LCx had mild plaquing. Right coronary artery was engaged using JR4 $6 F^{\prime}$ diagnostic catheter, showing mild plaquing.

The left main artery was engaged with VL3 (Cordis $®)$ guiding catheter and LAD wired with BMW (Abbott@)

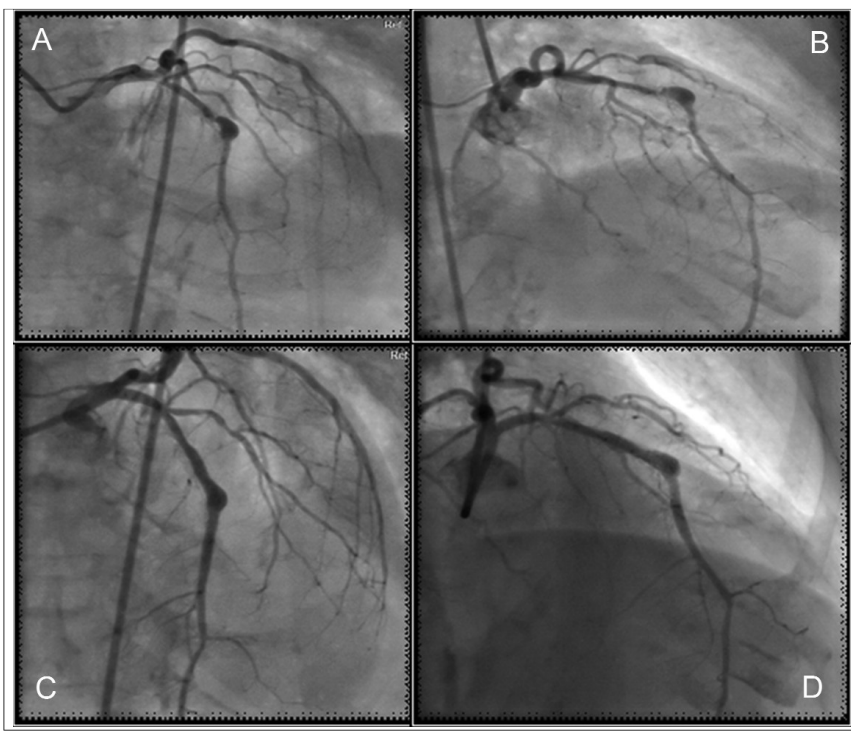

Figure 1: (A, B): Coronary angiogram showing tight in stent re-stenosis (ISR) in Left Anterior Descending (LAD) stent, followed by coronary artery aneurysm in the prior stent. (C, D) Angiogram after stenting of prior mid Left Anterior Descending (LAD) stent and coronary aneurysm. Post PCI TIMI III flow was achieved in $L A D$. 


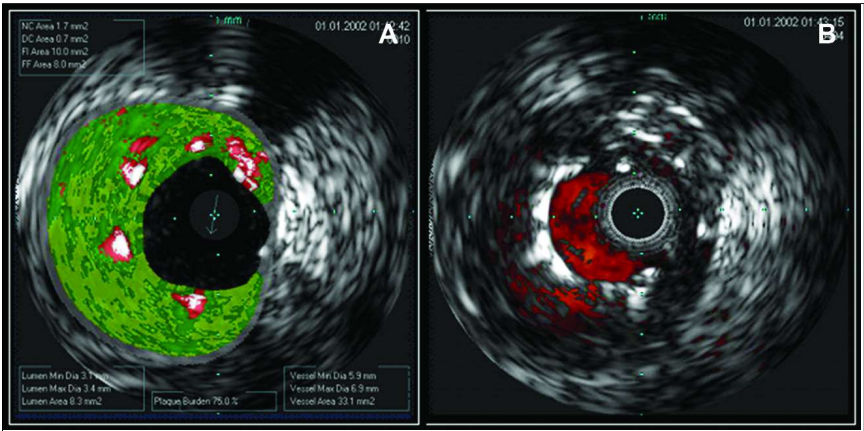

Figure 2: (A) Intravascular ultrasound (IVUS) showing ISR along with aneurysm in prior mid Left Anterior Descending (LAD) stent. (B) Well deployed and apposed stent with minimal gap in between two stent struts visualised.

0.014 inch wire. Mid-LAD ISR was predilated with Saphire II (OrbusneichTM) 2.0×10 mm at 6 atm (Figures 1C and 1D). Intravascular ultrasound (IVUS) revealed ISR in proximal part of mid-LAD stent with aneurysm (Figure 2A). Xience xpedition (Abbott $\AA$ ) $2.5 \times 33 \mathrm{~mm}$ (DES) was deployed into mid-LAD stent including proximal and distal segments to it at $10 \mathrm{~atm}$. Stent was post-dilated sequentially with NC TREK (Abbott $®$ ) $2.5 \times 15 \mathrm{~mm}$ at $14-20 \mathrm{~atm}$ and NC TREK (Abbott $囚) 3.0 \times 8$ $\mathrm{mm}$ at 10-16 atm. At the end of procedure, IVUS revealed well-deployed and apposed stent with minimal gap in between two stent struts (Figure 2B). TIMI-III flow was achieved in LAD.

The patient was kept on dual antiplatelets (DAPT) and glycoprotein Ilb/llla inhibitor (Gpllb/llla) infusion. She improved over the course of admission.

\section{DISCUSSION}

DES are impregnated with drugs which interfere with inflammatory pathways and neo-intimal proliferation, however, these local effects induce delayed reendothelialisation, hypersensitivity reactions, and inflammatory changes of vessel wall, leading to CAN formation.6,7 Coronary angiography is gold standard for diagnosing CAN, yet it only gives information regarding lumen of the arteries. ${ }^{2}$ IVUS allows detailed characterisation of the aneurysms, as it visualises layers of the coronary arteries and differentiates between true and pseudo-aneurysms. ${ }^{8}$ Aoki et al. have classified CAN into 3 types. ${ }^{2}$ Type- 1 occurs within 1 month secondary to mechanical injury to the arterial wall. Type-2 occurs after 6 months of stent placement as an arterial wall response to DES. Type-3 are infectious mycotic aneurysms.

There are no documented guidelines for management of stent-related CAN. The only available data are isolated management protocols from individual case reports. These include observation, antiplatelet treatment, coiling or surgical excision. ${ }^{9}$ Aoki et al proposed a management plan. ${ }^{2}$ They suggest percutaneous treatment with stent graft, bavemetel stent (BMS) or surgery for large (more than 2 times the size of reference vessel) or symptomatic pseudo-aneurysms and large and/or symptomatic true aneurysms. For small or asymptomatic true and pseudoaneurysms, followup angiography at 3 to 6 months is suggested. For small true aneurysms and those large asymptomatic with no change in follow-up angiography, careful observation and DAPT is suggested. We used IVUS, as it aptly detects malapposition of DES and vessel wall and also defines the size of aneurysms especially in cases of DES thrombosis. ${ }^{10}$ There is a lack of guidelines on the choice of antiplatelet therapy and duration of antiplatelets in cases of CAN. We decided to keep our patient post-PCI on DAPT and Gpllb/llla infusion for optimal antiplatelet effect.

CANs are rare vascular complications of DES. Their optimum treatment is still debatable, yet the application of DES under IVUS guidance can result in successful treatment.

\section{REFERENCES}

1. Syed M, Lesch M. Coronary artery aneurysm: a review. Prog Cardiovasc Dis 1997; 40:77-84.

2. Aoki J, Kirtane A, Leon MB, Dangas G. Coronary artery aneurysms after drug-eluting stent implantation. JACC Cardiovasc Interv 2008; 1:14-21.

3. Slota PA, Fischman DL, Savage MP, Rake R, Goldberg S. Frequency and outcome of development of coronary artery aneurysm after intracoronary stent placement and angioplasty. STRESS Trial Investigators. Am J Cardiol 1997; 79:1104-6.

4. Patil P, Sethi A, Kaul U. Stent thrombosis with an aneurysm 7 years after a drug eluting stent implantation. Indian Heart $J$ 2014; 66:216-9.

5. Kadakia MB, Epps KC, Julien ME, Ogbara J, Giri J, Kolansky DM, et al. Early aneurysm formation after everolimus-eluting stent implantation. Circ Cardiovasc Interv 2014; 7:266-7

6. Daemen J, Serruys PW. Drug-eluting stent update 2007: part I. A survey of current and future generation drug-eluting stents: meaningful advances or more of the same? Circulation 2007; 116:316-28

7. Nakazawa G, Finn AV, Virmani R. Vascular pathology of drugeluting stents. Herz 2007; 32:274-80.

8. Ge J, Liu F, Kearney P, Gorge G, Haude M, Baumgart D, et al. Intravascular ultrasound approach to the diagnosis of coronary artery aneurysms. Am Heart J 1995; 130:765-71.

9. Hakeem A, Karmali K, Larue SJ, Bhatti S, Chilakapati V, Samad Z, et al. Clinical presentation and outcomes of drugeluting stent-associated coronary aneurysms. Eurolntervention 2011; 7:487-96.

10. Alfonso F, Perez-Vizcayno MJ, Ruiz M, Suarez A, Cazares M, Hernandez $\mathrm{R}$, et al. Coronary aneurysms after drug-eluting stent implantation: clinical, angiographic, and intravascular ultrasound findings. J Am Coll Cardiol 2009; 53:2053-60. 